Article

\title{
Historic Environmental Vulnerability Evaluation of Traditional Villages Under Geological Hazards and Influencing Factors of Adaptive Capacity: A District-Level Analysis of Lishui, China
}

\author{
Sheng Liu ${ }^{1,2, * \mathbb{C}}$, Jian Ge ${ }^{1}$, Wangming $\mathrm{Li}^{1}{ }^{1}$ and Ming Bai ${ }^{3}$ \\ 1 College of Civil Engineering and Architecture, Zhejiang University, Hangzhou 310058, China; \\ gejian1@zju.edu.cn (J.G.); ghliwangming@zju.edu.cn (W.L.) \\ 2 Zhejiang University City College, Hangzhou 310011, China \\ 3 Zhejiang University Urban-Rural Planning \& Design Institut, Hangzhou 310030, China; \\ 3120102646@zju.edu.cn \\ * Correspondence: lius@zucc.edu.cn
}

Received: 19 January 2020; Accepted: 5 March 2020; Published: 12 March 2020

\begin{abstract}
The historic environmental vulnerability of traditional villages (HEVTVs) is distinctly differentiated; however, the priority of relevant emergency management practices still lacks appropriate evaluation. This study proposes a new assessment system to quantify HEVTVs at the district level and an extended analysis of the influencing factors of adaptive capacity. This provides a basis to classify the emergency management of villages under geological hazard risks. Based on the coupled human-environment system, this research designed the assessment with three criteria, six factors, and 13 indexes from the perspective of HEVTVs. Furthermore, a demonstration test was conducted of 148 traditional villages in Lishui, China. The results showed that $64.19 \%$ of HEVTVs in Lishui were moderate or above, and that villages with very high vulnerability were mainly distributed at mid-elevation of mountains with strongly sloping terrain. In contrast, low-vulnerability villages were generally on plains at low altitudes. Furthermore, three high-vulnerability clustering groups were identified as critical improvement targets for which special zoning strategies should be proposed. Five influencing factors were found to be strongly related to the adaptive capacity, indicating a spatial variation of the impact intensity. This could be applied to streamline vulnerability optimization strategies according to local conditions.
\end{abstract}

Keywords: historic environmental vulnerability; emergency classification; quantitative assessment; coupled human-environment system

\section{Introduction}

\subsection{Background}

China initiated the protection of traditional village in 2012 and identified 6799 at the national level. Traditional villages are usually villages that formed in the early history of China, that have precious traditional resources, and that have specific historical, cultural, scientific, artistic, social, and economic values that are worth protecting [1]. Currently, global research on traditional villages generally focuses on their sustainable development [2-4], while studies on their disaster prevention mainly focus on fires [5] and floods [6] However, China is prone to geological disasters, and traditional villages are mostly located in mountainous areas with frequent geological hazards, limited disaster prevention, and few mitigation facilities [7]. Thus, faced with sudden geological hazards caused by climate change, 
a large number of ancient buildings, trees, and archways in traditional villages may collapse and become damaged, causing significant challenges to inheritance protection.

Mountainous areas in Zhejiang Province typically have steep topographies and are therefore vulnerable to typhoons, rainstorms, landslides, and debris flows. Lishui, a traditional village-gathering area in the southwest of Zhejiang Province, is a prefecture-level city area with $90 \%$ mountainous terrain and is situated in a region with the highest frequency of geological disasters in the province [8]. According to the data in the 13th Five-Year Plan for Geological Disaster Prevention and Environmental Protection of Lishui, by 2015, Lishui had 1696 identified hidden danger points for geological disasters, 265 collapses, 1021 landslides, 397 debris flows in hidden valleys, 12 ground subsidences, and one place with expansive soil. These frequent geological disasters caused irreversible damage to the historic environment of traditional villages. For example, after the typhoon "Sangmei" in 2006, the debris flow caused by heavy rain hit Shimoxia Village in Qingyuan County, Lishui, burying a large number of ancient folk houses, trees, and lanes (Figure 1a) [8]. Moreover, in 2015, heavy rain affected Lidong village, Lishui, causing a landslide of more than $300,000 \mathrm{~m}^{3}$ which buried 27 and flooded 21 traditional buildings (Figure 1b) [9]. Therefore, the emergency management of the historic environment of traditional villages needs to be urgently strengthened at the regional level. However, many traditional communities in Lishui are widely distributed thus having different geological hazard susceptibilities, historic environment types, and adaptabilities. This causes significant disparity within the historic environmental vulnerability of traditional villages. Furthermore, neither the degree nor the feature of the vulnerability differentiation is explicit to date. It is therefore difficult to establish the basic unit for the classification of targeted emergency management.

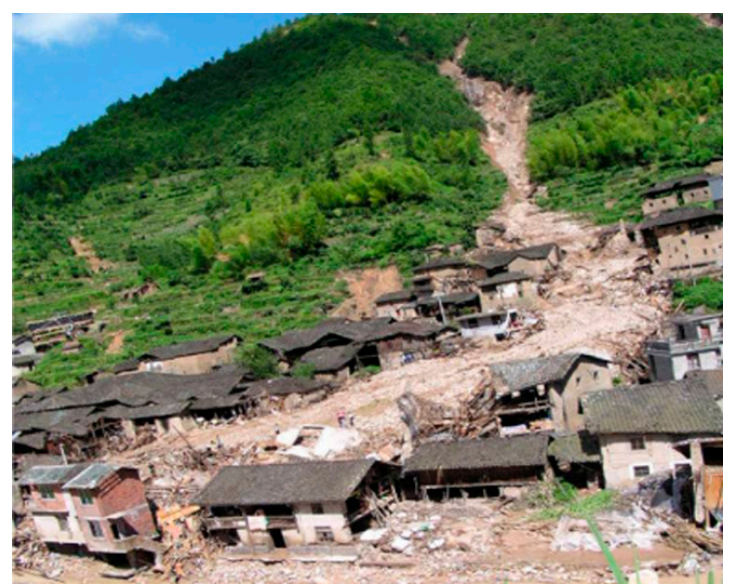

(a)

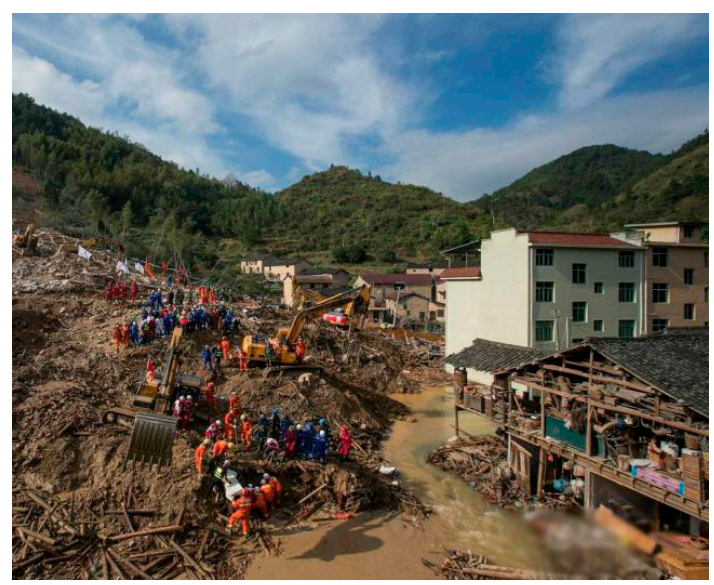

(b)

Figure 1. Damage to the historic environment of traditional villages caused by geological disasters. (a) Scene after a debris flow at Shimuxia Village in Qingyuan County, Lishui, on August 11, 2006, Photo: AnpingPAN [8]; (b) scene of landfall at Lidong Village in Liandu District, Lishui, August 11, 2006.

Thus, this study introduces core concerns: under geological hazard risk, the differentiation of traditional villages' historic environmental vulnerability is distinct, but the priority of related emergency management practices still lacks scientific evaluation. In this case, a specific vulnerability assessment system needs to be urgently developed, and the influencing factors of their adaptive capacity (AC) need to be explored. The goal should be the effective avoidance of damage caused by geological hazards to inheritance blocks of the historic environment of traditional villages.

\subsection{Literature Review}

The term vulnerability first appeared in 1945 in White's research on flood disasters [10]. The Second Assessment Report of the Intergovernmental Panel on Climate Change (IPCC) defined "vulnerability" 
as the extent to which a system may be damaged or harmed, depending on exposure, sensitivity, and AC [11,12]. This framework considers the coupled human-environment system, from both human and biophysical perspectives [13], and has been generally accepted [14-16]. In the field of vulnerability caused by geological hazards, research has not only widely applied this definition framework [17-19] but also continuously innovated new methods [20,21] and data applications [22,23]. However, several limitations still affect vulnerability research objects, especially in the field of rural villages. At present, studies on rural villages mainly focus on the vulnerability of whole villages $[19,24]$. Studies on specific vulnerabilities have only investigated a few domains such as the traffic environment [25], landscape environment [26], buildings [18], and risk perception [8]. However, studies on the vulnerability of villages' historic environment remain underdeveloped.

The historic environment has received much attention in the fields of archaeology and historical culture. These fields investigate the overall state of the physical environment which is composed of cultural heritage and closely related to the land within a specific range [27]. Although the historic environment has inherent flexibility, its vulnerability has become increasingly prominent. Its natural exposure to increased environmental pressures and historical protection requirements often limit the enhancement of its material performance [28]. Thus, many scholars have begun fragility research of the historic environment, investigating various disasters including climate disasters [29], geological disasters [30], fires [31], earthquakes [32,33], floods [34] as well as marine and aeolian processes [35].

However, these studies mainly focused on subjects with a high level of historic environmental protection such as world heritage sites [29,30] and famous historical and cultural cities [33]. Relatively little concern has been expressed for the historic environmental vulnerability of villages, especially traditional villages. Moreover, the existing literature on similar evaluation objects is still limited to assessment types and samples and only concentrated on a single category [24] or the dissection of small samples [26,31,36]. For instance, the study by Zhou [26] offered a quantitive assessment of three typical traditional villages by proposing a landscape vulnerability evaluation of traditional villages. However, this approach leaves a gap in their regional differentiated vulnerability features. Similar large-scale and small-unit vulnerability assessments have been conducted such as the geological hazard exposure and risk awareness study of 981 world heritage sites around the world [30] and the intrinsic vulnerability assessment of 15,285 agricultural villages in the Himalayas [37]. However, these study subjects differ from the historic environment of traditional Chinese villages which cannot be directly transferred. It is still necessary to construct a regional scale evaluation that matches the characteristics of the historic environment of traditional villages which can afford full types and large samples of empirical studies and quantitative interpretations.

In summary, previous studies have the following shortcomings: (1) geological hazard-affected bodies lag behind, since previous vulnerability studies have not addressed the historic environment of villages as the carriers of disaster; (2) similar particular evaluation objects are limited in type and scale; yet, they lack quantitative classification of large samples at the district level. This gap not only prevented researchers from specifying regional differences in vulnerability features and impact factors of AC but also failed to supply policymakers with differentiated emergency management measures from a macro-perspective. Therefore, this paper aimed to fill the following current knowledge gaps: (1) develop the connotation and composition of this underdeveloped historic environmental vulnerability of traditional villages (HEVTVs); (2) develop a scientific measurement of large samples for a small-unit evaluation system, suitable for the quantitative classification of the HEVTVs.

\subsection{Research Aims}

This study had two primary aims: (1) to propose a new assessment system to quantify the previously unidentified vulnerability of traditional villages' historic environment at the district level; (2) to investigate the influencing factors of $\mathrm{AC}$ and their distribution differences, provide a basis to lower their vulnerability to the geological hazard risk, and classify prudent emergency management practices. 
Therefore, based on the coupled human-environment system, a connotation of the fragility of the historical environment of traditional Chinese villages, and a vulnerability assessment framework suitable for large-scale calculation from the view of exposure, sensitivity, and AC were constructed firstly. Secondly, this study chose Lishui, a traditional village-gathering area with hidden geological hazards in China, as an example. A quantitative evaluation of the degree of each traditional village's historic environmental vulnerability and their spatial distribution and correlation characteristics were conducted. Finally, the study further targeted the AC, which is critical to reduce vulnerability, and both ordinary least squares (OLS) regression and geographically weighted regression (GWR) models were used to analyzing its influencing factors and their spatial intensity variation, respectively.

This paper provides new ideas and empirical results on the scientific measurement of large samples for small unit vulnerability evaluation related to the historic environment of traditional villages. The application of this evaluation method offers insight into the following contents: (1) by distinguishing the degrees, the spatial distributions, the terrain features and the agglomeration characteristics of HEVTVs, the scientific regional vulnerability classification and the emergency management priority setting for large samples can be realized; (2) streamlining HEVTVs' optimization strategies according to local conditions can be achieved according to the factors that influence AC and their intensity characteristics in different areas.

\section{Study Area and Data Source}

\subsection{Study Area}

Lishui offers excellent research value and typicality for the exploration of the historic environmental vulnerability of traditional villages under geological disaster risks. It has a total area of $17,276.93 \mathrm{~km}^{2}$ with $88.4 \%$ mountainous terrain, and lies in the south of Zhejiang Province, China. The region has an underdeveloped economy, and the per capita income of its rural residents was 18,072 Yuan (USD 2583) in 2017 [38]. This region has a subtropical humid monsoon climate with an average annual rainfall of 1313.1-1740.8 $\mathrm{mm}$ and a large amount of concentrated heavy rainfall which is the leading factor that induces geological disasters [39]. Thus, combined with its complex geological environment, $97.8 \%$ of its district is prone to geological disasters, mainly including landslides, collapses, and debris flows. Moreover, it is also one of the territories that suffers the most severe geological disaster losses on the east coast of China. From 2011 to 2015, a total of 484 geological disasters occurred here, resulting in 56 casualties and direct economic losses of 136.048 million Yuan [39]. In addition, this region is the only experimental area for the protection and utilization of traditional villages in China and has the first national demonstration county, Songyang, for the protection and development of traditional villages. By 2017, Lishui had 158 traditional villages which were included in the first four batches of the Chinese traditional villages list. Lishui is also the prefecture-level city area with the third-most national traditional villages.

This study covers all national traditional villages in the whole region of Lishui including the area of one municipal district, one county-level city, and seven counties (Figure 2). After collecting Lishui's survey registration forms of the first four batches of Chinese traditional villages, 10 village files were missing. Therefore, the remaining 148 traditional villages with sufficient data were investigated. These 148 villages are $65 \%$ mountainous-type, $29 \%$ hilly-type, and $6 \%$ plain-type with many differences in their economies, geological disaster susceptibilities, degree of rural hollowing, historical environmental scales, and types. Thus, both the value and space distribution of the vulnerability of the historic environment in each village are highly diverse. 


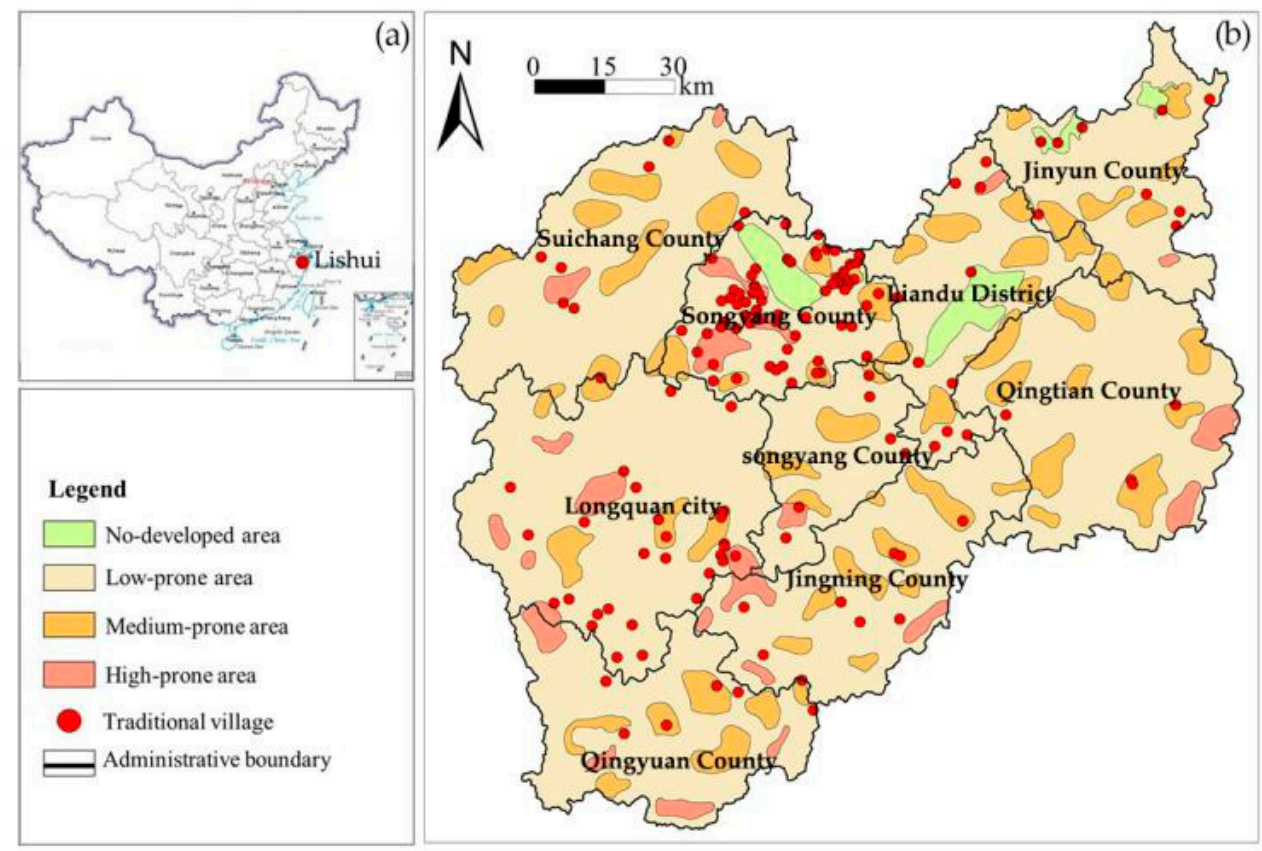

Figure 2. (a) Location of Lishui; (b) geological hazard distribution and susceptibility zoning map of Lishui (data source: Land Resources Bureau of Lishui, 2017) combined with the locations of traditional villages (the geocodes of the villages were extracted from the Gaode open platform [40].

\subsection{Data Sources}

The associated data sources utilized in this study include both open-source data and traditional statistics data. For open-source data, the digital elevation model (DEM) data set with a $30 \times 30 \mathrm{~m}$ horizontal resolution, the 1:10,000 road network data, and the water system data were obtained from the geographical information monitoring cloud platform [41]. Furthermore, the city and county administrative division data (2015) and the GDP grid data set at a $1 \mathrm{~km} \times 1 \mathrm{~km}$ resolution (2015) originated from the resources and environmental data of the cloud platform [42]. Lishui's Weibo check-in data (2017) were obtained via Sina Weibo's open platform of application programming interfaces (APIs). The points of interest (POI) data of Lishui (2017) were also acquired. These data included the coordinate data of villages, townships, and highway entrances, and geocoding was used to extract data from the Gaode open platform [40]. Moreover, the traditional statistics data were obtained from Lishui's Housing and Construction Bureau, Meteorological Bureau, and Land Resources Bureau. These data included Lishui's survey registration forms of the first four batches of Chinese traditional villages, a meteorological disaster risk zoning map of Lishui, the 13th Five Year Plan for the prevention and protection of geological disasters in Lishui, and the geological hazards distribution and susceptibility zoning map of Lishui. These data sources were used in support of the vulnerability evaluation indexes and the influencing factors of AC in this study as shown in Table 1. 
Table 1. Indexes of the historic environmental vulnerability of traditional villages.

\begin{tabular}{|c|c|c|c|c|c|}
\hline Criteria & Factors & Indexes & Descriptions & Methods & Data \\
\hline \multirow{5}{*}{ Exposure (E) } & \multirow{3}{*}{$\begin{array}{l}\text { Intensity of geological } \\
\text { hazard risk events }\end{array}$} & E1 Topographic relief & $\begin{array}{l}\text { Number of altitude changes between the highest } \\
\text { point and the lowest point within a unit }\end{array}$ & $\begin{array}{c}\text { The bayesian change-point analysis showed that the best statistical unit for } \\
\text { Lishui region is } 0.176 \mathrm{~km}^{2}\end{array}$ & (1) \\
\hline & & $\begin{array}{l}\text { E2 Level of geological } \\
\text { hazard risk }\end{array}$ & Grade of geological disaster susceptibility & Score 1-4, according to the grade of no, low, medium, and high susceptibility. & (2) \\
\hline & & E3 Level of rainstorm risk & Grade of rainstorm disaster susceptibility & Score $1-4$, according to the rainfall contour gradient & (3) \\
\hline & \multirow{2}{*}{$\begin{array}{l}\text { Scale of hazard-affected } \\
\text { bodies }\end{array}$} & $\begin{array}{l}\text { E4 Proportion of the } \\
\text { traditional building area }\end{array}$ & $\begin{array}{l}\text { Area percentage of traditional buildings } \\
\text { (cultural relics, historic buildings, and traditional } \\
\text { residences) among the village's overall buildings }\end{array}$ & Direct use & (4) \\
\hline & & $\begin{array}{l}\text { E5 Number of historic } \\
\text { landscape elements }\end{array}$ & $\begin{array}{l}\text { Number of landscape relics such as ancient } \\
\text { roads, bridges, culverts, walls, wells, ponds, } \\
\text { and trees }\end{array}$ & Direct use & (4) \\
\hline \multirow{5}{*}{ Sensitivity ( $\mathrm{S}$ ) } & \multirow{3}{*}{$\begin{array}{l}\text { Sensitivity of traditional } \\
\text { buildings }\end{array}$} & $\begin{array}{l}\text { S1 Sensitivity of } \\
\text { traditional building } \\
\text { materials }\end{array}$ & $\begin{array}{l}\text { Possibility of the damage of traditional } \\
\text { buildings materials after geological hazards }\end{array}$ & $\begin{array}{l}\text { Score 1-5, according to stone, black brick, clay brick, rammed earth, } \\
\text { and wood, multiplied by the percentage of each material and then summed }\end{array}$ & (4) \\
\hline & & $\begin{array}{l}\text { S2 Sensitivity of } \\
\text { traditional buildings' } \\
\text { structure }\end{array}$ & $\begin{array}{l}\text { The possibility of buildings structures' damage } \\
\text { to geological hazards }\end{array}$ & $\begin{array}{l}\text { Score 1-5, according to masonry, brick, wood, wood, civil, soil, multiplied by } \\
\text { the percentage of each type of structure and then summed }\end{array}$ & (4) \\
\hline & & $\begin{array}{l}\text { S3 Age of traditional } \\
\text { buildings }\end{array}$ & $\begin{array}{l}\text { Average year of construction of the traditional } \\
\text { buildings in the village }\end{array}$ & $\begin{array}{l}\text { Score 1-5, according to the period of the Republic of China and later, Qing, } \\
\text { Ming, Yuan, and Song Dynasty, multiplied by the percentage of each year of } \\
\text { built type and summed }\end{array}$ & (4) \\
\hline & \multirow{2}{*}{$\begin{array}{l}\text { Sensitivity of historic } \\
\text { landscape elements }\end{array}$} & $\begin{array}{l}\text { S4 Sensitivity of materials } \\
\text { of historic landscape } \\
\text { elements }\end{array}$ & $\begin{array}{l}\text { Possibility of historic landscape damage in } \\
\text { geological hazards }\end{array}$ & $\begin{array}{l}\text { Score 1-5, according to stone, black brick, clay brick, rammed earth, } \\
\text { and wood, multiplied by the percentage of each material and then summed }\end{array}$ & (4) \\
\hline & & $\begin{array}{l}\text { S5 Age of historic } \\
\text { landscape elements }\end{array}$ & $\begin{array}{l}\text { Average year of construction of the historic } \\
\text { landscape elements in the village }\end{array}$ & $\begin{array}{l}\text { Score 1-5, according to the period of the Republic of China and later, Qing, } \\
\text { Ming, Yuan, and Song Dynasty, multiplied by the percentage of each year of } \\
\text { built type and summed }\end{array}$ & (4) \\
\hline \multirow{3}{*}{$\begin{array}{l}\text { Adaptive } \\
\text { capacity (AC) }\end{array}$} & Human capital & $\begin{array}{l}\text { A1 Occupancy rate of } \\
\text { traditional buildings }\end{array}$ & $\begin{array}{l}\text { Percentage of inhabited traditional buildings } \\
\text { among the village's buildings }\end{array}$ & Direct use & (4) \\
\hline & \multirow{2}{*}{ Economic wealth } & $\begin{array}{l}\text { A2 Annual per-capita } \\
\text { income of the villager }\end{array}$ & $\begin{array}{l}\text { Average annual income per resident in one } \\
\text { traditional village }\end{array}$ & Direct use & (4) \\
\hline & & $\begin{array}{l}\text { A3 Annual village's } \\
\text { collective income }\end{array}$ & $\begin{array}{l}\text { Annual collective economy of the village, such } \\
\text { as income from commune-run enterprises and } \\
\text { institutions, accumulation fund, etc. }\end{array}$ & Direct use & (4) \\
\hline
\end{tabular}

Data: (1) digital elevation model (DEM) data set with a $30 \times 30 \mathrm{~m}$ horizontal resolution; (2) geological hazards distribution and susceptibility zoning map; (3) meteorological disaster risk zoning map; (4) survey registration forms of national traditional villages. Spatialization: the spatial data of each traditional village point was extracted from POI as base, using ArcGIS 10.6 to spatially join each indicator value to the point. 


\section{Methods}

\subsection{Interpretation of the Historic Environmental Vulnerability of Traditional Villages (HEVTVs)}

At present, scholars generally assume that the historic environment refers to the overall material environmental state which is composed of the cultural heritage and closely related to a specific range of land [27]. However, land-related cultural heritages in traditional villages are mainly composed of traditional buildings and historic landscape elements [43]. Therefore, the HEVTVs can be assumed as the overall physical environment composed of traditional buildings and historic landscape elements within the scope of the village. Among these elements, traditional buildings refer to cultural relics, historic buildings, and traditional residences, while historic landscape elements refer to ancient roads, bridges, culverts, walls, wells, ponds, trees, and similar items [44]. Based on the coupled human-environment vulnerability assessment system proposed by Eakin [13], this study considered the historic environmental vulnerability from both biophysical and human perspectives, as a combination of exposure, sensitivity, and adaptive capacity. In summary, this research regarded HEVTVs as the historic environment of traditional villages (including traditional buildings and historic landscape elements) that is susceptible to damage or negative effects because of the environmental exposure to geological disasters as well as the lack of corresponding anti-disturbance capabilities and risk-coping abilities.

\subsection{Selection of Vulnerability Indexes}

Based on this connotation, the sustainable inheritance of the historic environment was identified as the goal of selection and its criteria, factors, and indexes were set-up based on the comprehensively coupled human-environment system, the inducer of geological disaster risk, and the composition of the historic environment. In accordance with the principles of scientificity, comparability, and comprehensiveness, this system referred to many other materials, such as the afore-mentioned literature, as well as the opinions of experts, traditional village managers, and local respectable persons. Moreover, the feasibility of the indicator system for collecting large-sample data in underdeveloped regions was fully considered. The assessment consisted of three criteria, six factors, and 13 indexes (Table 1).

\subsubsection{Exposure}

The exposure of the historic environment to geological disaster risk is related to the interaction between risk intensity and the scale of disaster-affected bodies. Firstly, since this study focused on the geological hazards of landslides, collapses, and debris flows, the occurrence of such disasters is not only connected to the geographical features but also correlates with concentrated heavy rainfalls $[45,46]$. Therefore, disaster inducers such as topographic relief (E1), the level of geological hazard risk (E2), and the level of rainstorm risk (E3) were selected, all of which are critical for the intensity of geological hazard risk events [25,46]. Moreover, these can jointly indicate the regional exposure of the historic environment. Thus, the higher these factors are, the more significant the intensity of the geological disaster risk will be. Secondly, since the exposure is closely related to the scale of hazard-affected bodies [18,20], the constitute of the historic environment was used as basis. The proportion of traditional villages (E4) and the number of historic landscape elements (E5) were chosen to represent the scale of potential disaster carriers. The higher these indexes, the greater their exposures.

\subsubsection{Sensitivity}

Sensitivity refers to the degree to which the historic environment is easily changed or affected by geological hazards. This study selected the physical property connected with the anti-disturbance performance of the research objects, from the aspects of traditional architecture and historical landscape, which are the two categories of the historic environment. Among these, the sensitivities of materials (S1) $[24,26]$ and structures (S2) [18,20], as well as their ages (S3) [26] are commonly used indicators of the disaster resistance of traditional buildings. Historic landscape elements are similar; however, because 
they do not involve structural issues, the material sensitivity and the age of objects are frequently used variables [29]. Thus, the higher the sensitivities of both material and structure, and the older the objects, the more susceptible they will be to geological disasters.

\subsubsection{Adaptive Capacity}

Adaptive capacity links to the ability of human-oriented disaster response subjects to reduce the negative impacts on the historic environment after the occurrence of geological disasters. This study mainly considered the capacities of the villages themselves and constructed the indicators from the perspectives of human capital and economic wealth, both of which are the most relevant variables for defining AC in rural areas [47,48]. With regard to human capital, traditional villages are severely hollowed because of urbanization thus causing the problem that many traditional buildings are uninhabited and lack householders to participate in the rescue of their own house. Therefore, the resident population cannot represent an adequate self-repair ability. However, the occupancy rate of traditional buildings (A1) is an appropriate indicator for self-reliant restoration [2,24]. The higher the occupancy rate, the stronger the motivation for self-recovery and AC. Therefore, the annual per-capita income of the villager (A2) and the annual collective income of the village (A3), which indicate whether they need external assistance to be able to execute repairs, are valid measures of AC [19]. The higher the per capita income and collective income are, the stronger the financial guarantee for self-repair and the AC will be.

\subsection{Evaluation Methods}

\subsubsection{Data Processing and Vulnerability Calculation}

Weightless indicators for integrated function operations are widely used in the field of vulnerability assessment [25]. Compared with weighted variables, the expression or use of composite indicators does not show low effectiveness but intelligibility since it does not change the information conveyed by the composite index [49]. This study evaluated the HEVTV as a function of exposure, sensitivity, and adaptive capacity, using not only normalization to standardize the data, but also the mean value method under weightless conditions to aggregate indicators.

The HEVTV index assessment model is as follows:

$$
\begin{gathered}
V=E+S-A C \\
E=\frac{1}{n} \sum_{i=1}^{n} N_{e i} ; S=\frac{1}{n} N_{s i} ; A C=\frac{1}{n} \sum_{i=1}^{n} N_{a i} ; i=1,2, \ldots, n
\end{gathered}
$$

$V, E$, and $S$ represent the indexes of vulnerability, exposure, and sensitivity, respectively, while Nei, Nsi, and Nai represent the normalized values of the indicators of the exposure, sensitivity, and $A C$.

\subsubsection{Analysis Model}

Firstly, according to the calculated results of vulnerability, this study used both global spatial autocorrelation [50] and local spatial autocorrelation [51] to conduct the spatial analysis. Throughout this process, the global autocorrelation was used to describe the overall distribution of the vulnerability of the historic environment of 148 traditional villages to determine whether any regional agglomeration of HEVTV exists. Local space autocorrelation was used to measure the correlation of the HEVTV between a single village and neighboring villages, to identify high vulnerability groups. Secondly, OLS [52] and GWR [53] regression were used to analyze the influencing factors of AC. For this step, this study used OLS regression to analyze the parameters globally and then selected the variables that passed the significance test. Then, the GWR model was applied for local parameter analysis, which was spatialized by ArcGIS 10.6 software to explore the characteristics of spatial variation. 


\subsubsection{Validation}

To validate the assessment results of the HEVTV index in Lishui, this study used a sample segmentation test. According to the geographical location of the village, the data were divided into two subsets, north and south (91 villages in the north and 57 villages in the south). Then, their HEVTV indexes were calculated independently. In this case, both the extreme values of the indicators and their standardized results (used to calculate these two new samples) will differ from the previous values. The next step verified whether the evaluation results would change after the sample segmentation based on whether the HEVTV value sets were significantly different between the old and new data samples. Thus, Spearman correlation analysis was applied using SPSS 22.0. If the two new HEVTV value sets correlated significantly with the results of the original samples, the regional assessment results would not significantly change with changes of the variables caused by sample segmentation. This would further demonstrate that the method and the results are robust and stable.

For the OLS and GWR models that were established to analyze the impact factors of AC, this study used the goodness-of-fit test and standardized residuals analysis to determine whether heteroscedasticity problems exist. If the goodness of fit was high, the residual histogram would have a normal distribution trend; if the standard residual value passed the test of $[-2.5,2.5]$, there would be no obvious heteroscedasticity issue, and the regression model would be robust and suitable. At the same time, according to the evaluation criteria proposed by Fotheringham [54] (if the AICC value obtained from the GWR model decreased by more than 3 compared with that of the OLS, the GWR model would be superior), this study compared the superiority of OLS and GWR by the AICC value, to ensure the reliability of the applied model.

\section{Results}

\subsection{Spatial Distribution}

After the calculation of vulnerability, Arcgis 10.6 and its function of Jenks natural breaks optimization were used [55]. With this adapted function, each index of exposure, sensitivity, AC, and vulnerability was divided into five grades from very low to very high, followed by the spatial mapping of each dimension (Figure 3). According to the classification of slopes of the terrain, as suggested by Demek [53], and the classification of the basic terrestrial geomorphologic types of China [56], the geographical features of each dimension were statistically analyzed (Table 2).

Table 2. Topographic statistics of traditional villages with very high HEVTVs.

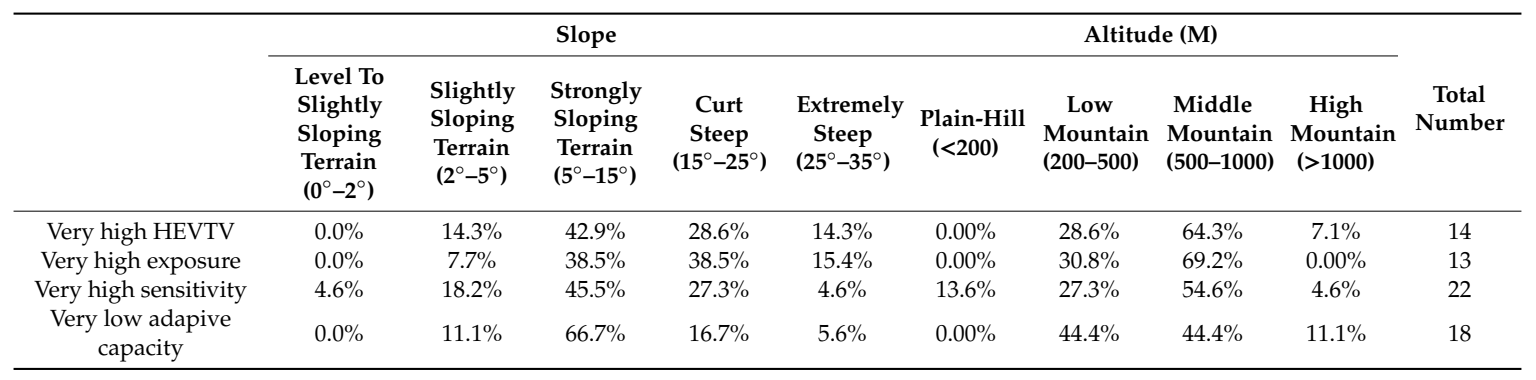




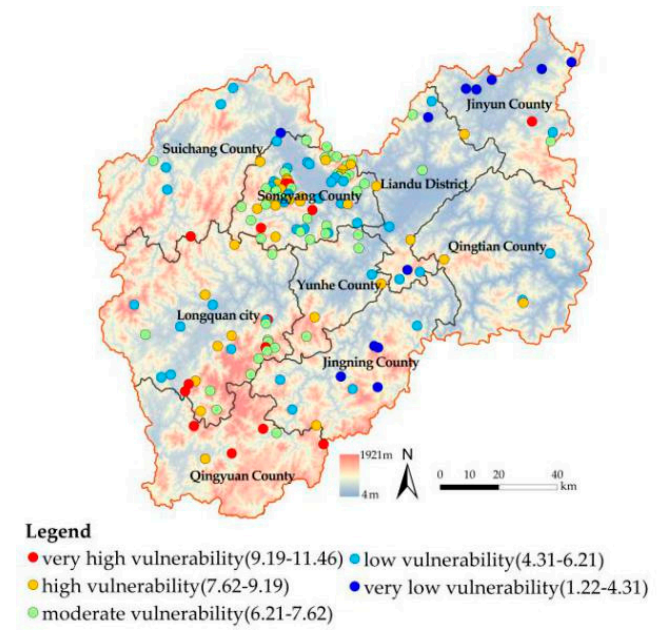

(a)

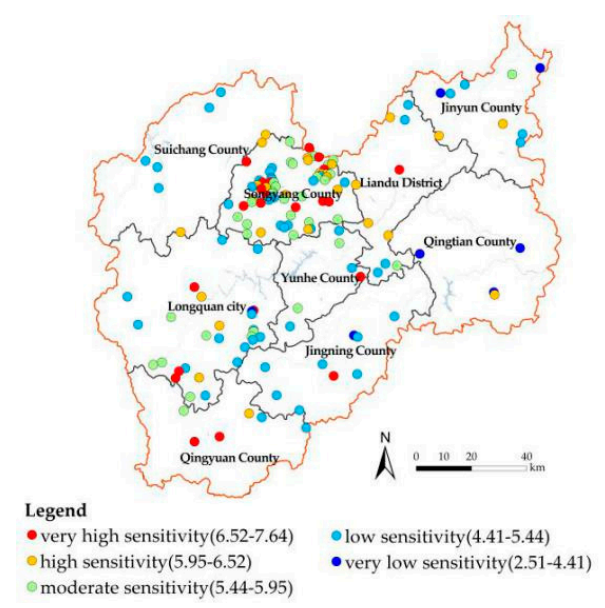

(c)

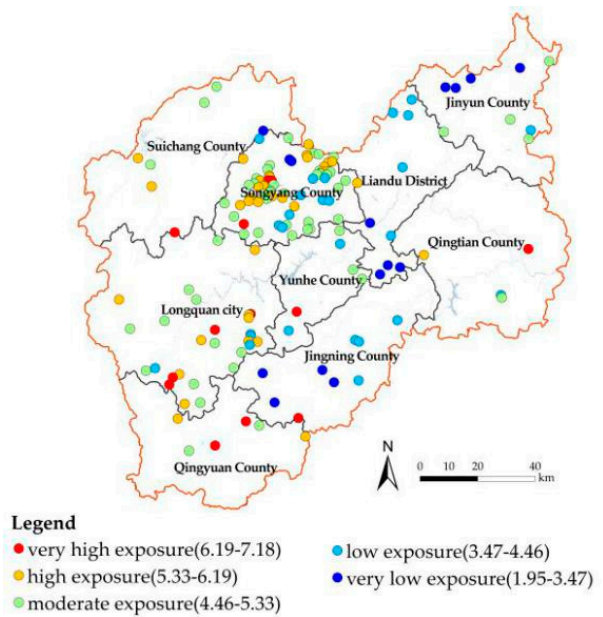

(b)

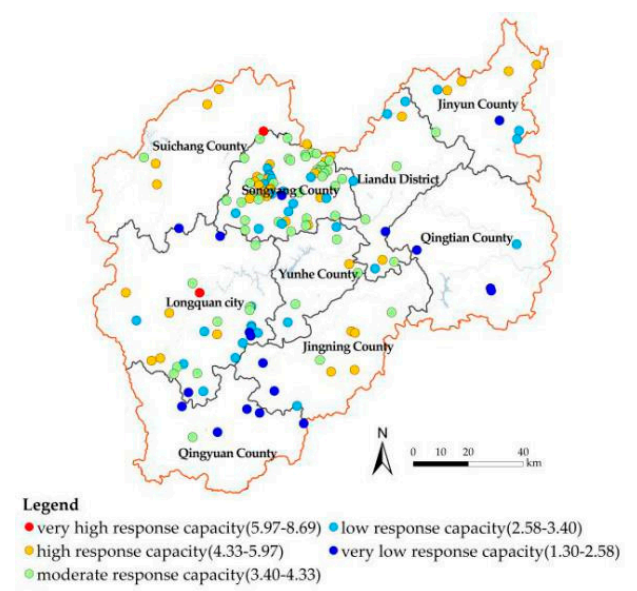

(d)

Figure 3. Spatial mapping of HEVTV measurement in Lishui: (a) vulnerability; (b) exposure; (c) sensitivity; (d) adaptive capacity.

\subsubsection{Exposure}

The exposure value of each traditional village in Lishui ranged from 1.95 to 7.18 , and $72.3 \%$ of the villages were within the medium and higher levels with values of 4.47-7.18 (Figure 3b). These were mainly situated in the western region, an area that is dominated by steep mountains and includes Songyang, Qingyuan, Longquan, and Suichang. However, in the eastern area where places are mainly situated in plains and hills, villages show much lower exposures (1.94-4.47) such as Liandu and Jingning. Moreover, $69.2 \%$ of villages with very high exposure are mainly distributed at elevations from 500 to $1000 \mathrm{~m}$.Most of them are situated within the strongly sloping and curt steep terrains (38.5\% each; Table 2). These results indicate a significant spatial exposure difference between the east and the west in Lishui and also suggest that very high-exposure villages are mainly located on mid-elevation mountains with strongly sloping terrains and curt steep landforms.

\subsubsection{Sensitivity}

The sensitivity value of each traditional village in Lishui ranged from 2.52-7.64 (Figure 3c), and $58.7 \%$ of these are within the medium and higher levels with values of 5.43-7.64 and are mainly located in Songyang, Liandu, Longquan, and Qingyuan. Moreover, $54.6 \%$ of the very high-sensitivity villages are located at elevations from 500 to $1000 \mathrm{~m}$, mainly with strong slopes (45.5\%), followed by 
curt steep terrains (27.3\%; Table 2). Traditional villages in such terrains have features of relatively inconvenient transportation and slow urbanization which may lead to high retention of the ancient and fragile historic environment thus explaining the high sensitivity value.

\subsubsection{Adaptive Capacity}

The AC value of each traditional village in Lishui ranged from $1.30-8.69$, and $73.7 \%$ are at medium and lower levels with values of 1.30-3.40 and are mainly located in the south and east of the region, located at the border junctions of Longquan, Qingyuan, and Jingning (Figure 3d). However, in the northern area, villages display much higher AC values, such as villages in Suichang, the AC values ranged within 3.40-8.69. Most of the villages with very low AC are located at low altitudes $(44.4 \%)$ and intermediate altitudes $(44.4 \%)$, mainly with strong slopes (45.5\%; Table 2$)$. These results indicate a distinct spatial difference of AC between the north and the south of Lishui, also suggesting that villages with very low $\mathrm{AC}$ are mostly located in medium to low altitudes with strongly sloping landforms.

\subsubsection{Vulnerability}

The value of HEVTVs ranged from 1.22 to 11.21. The sum of the percentage from moderate to very high demonstrates that $64.9 \%$ of HEVTVs in Lishui were at moderate grade or above (Table 3 ). Moreover, the overall spatial pattern of HEVTVs is high in the middle and low in the east and west (Figure 3a). Combined with the topographic layer, the vertical difference of the HEVETVs is significant, indicating that the vulnerability value was low in the northern plain, such as Jinyun county, and was generally high in southern mountainous areas such as Qingyuan County. Moreover, among villages with very high vulnerability, $64.9 \%$ are distributed at elevations from 500 to $1000 \mathrm{~m}$, firstly with strong slopes (42.9\%) and secondly with curt steep slopes (28.6\%; Table 2$)$.

This result was further analyzed in SPSS 22.0 using a Spearman bivariate correlation test of vulnerability index and DEM values of village elevation. A correlation coefficient of 0.362 was obtained, and both were significantly positively correlated at a level of 0.01 . This suggests that the value of HEVTVs was highly positively related to the elevation of the terrain thus explaining the reason why the very high-vulnerability villages are mostly distributed in mid-elevation mountains, while low-vulnerability villages are generally distributed in low-elevation areas.

Table 3. The grade division and statistics of HEVTVs in Lishui.

\begin{tabular}{cccc}
\hline Vulnerability Grade & Interval Value & Number & Percentage (\%) \\
\hline Very high & $9.19-11.76$ & 14 & 9.5 \\
High & $7.62-9.19$ & 33 & 22.3 \\
Moderate & $6.21-7.62$ & 48 & 32.4 \\
Low & $4.31-6.21$ & 41 & 27.7 \\
Very low & $1.22-4.31$ & 12 & 8.1 \\
Total & $1.22-11.21$ & 148 & 100 \\
\hline
\end{tabular}

\subsection{Vulnerability Validation}

A sample segmentation test was used to validate the results of the HEVTV index. According to the villages' geographical locations, the 148 villages were divided into two subsets (north and south), with 91 villages in the north subset and 57 villages in the south. Then, the vulnerability calculations of both subsets were independently conducted with spatialization. The distribution of HEVTVs in the two subsets (Figure 4a,b) coincided with the previous result (Figure 3a). The relationship was further confirmed through Spearman correlation analysis as indicated by significant correlation coefficients of 0.993 (north) and 0.802 (south). This indicated that the regional assessment results would not significantly change with changes in the variables caused by sample segmentation, suggesting the high accuracy and stability of the assessment of the HEVTVs. Thus, further analysis can be performed based on the obtained result. 


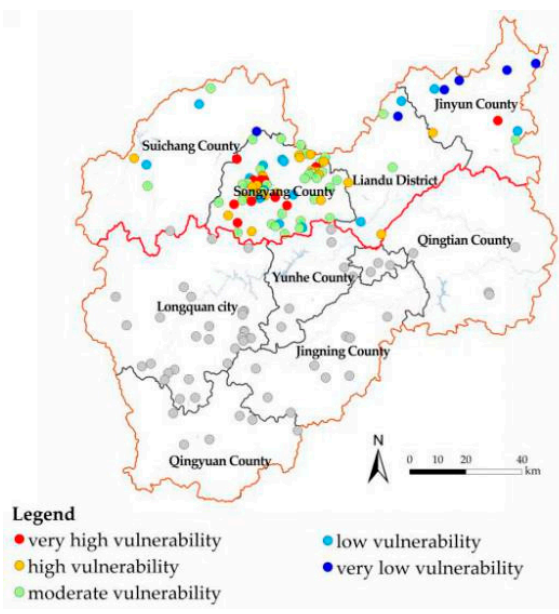

(a)

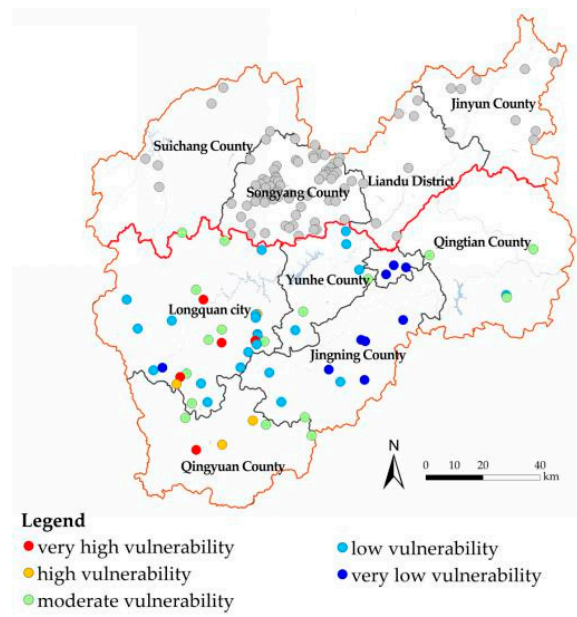

(b)

Figure 4. Spatial mapping of HEVTV measurement with the sample segmentation test. (a) North subset; (b) south subset.

\subsection{Spatial Autocorrelation}

The results of the global spatial autocorrelation analysis for all values of HEVETVs were statistically significant at the 99.9\% confidence level (Moran's $I=0.224, p=0.001, Z=4.647$ ). This indicates that the HEVETVs in Lishui had a significant spatial positive correlation, and that apparent regional agglomerations exist. This study further analyzed the local spatial correlation of 148 HEVETV values. There are five types of spatial autocorrelations. Interestingly, three remarkably high-high cluster groups were identified (Figure 5). The first group is located in the middle of Songyang, the second group is located at the junction of Songyang and Longquan, and the third group is located near the border of Qingyuan and Longquan counties. Combined with the value of vulnerability and its dimensions that were tested before, differences among these three groups were identified. In the first group, the values of vulnerability, exposure, and sensitivity were all mainly medium to very high with low-level AC. In the second group, with similar values of vulnerability and exposure, the values of sensitivity were much lower, ranging from low to medium. With regard to the third group, the values of $\mathrm{AC}$ were much lower, and the values of vulnerability ranged from high to very high, which was worse than the previous two groups. Overall, these $\mathrm{H}-\mathrm{H}$ clusters were identified as critical improvement targets, and the differences in their values indicate that regional policymakers may need classified emergy management to respond more effectively. Thus, relative suggestions are provided in the discussion section.

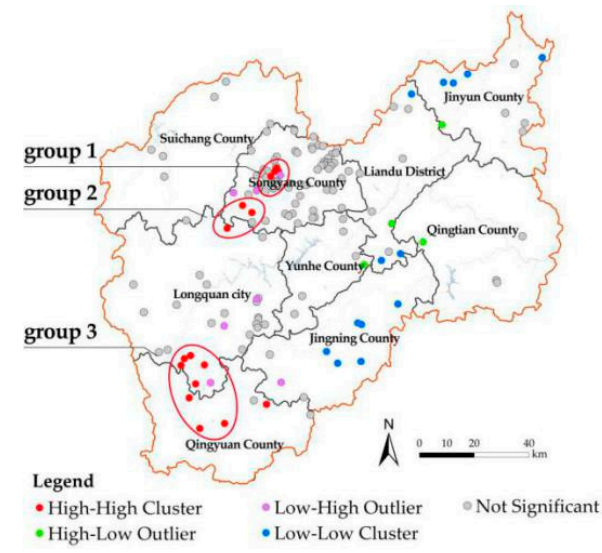

Figure 5. Local spatial correlation of 148 HEVETV values. 


\subsection{Impact Factor of Adaptive Capacity}

The vulnerability assessment used in this paper is mainly composed of three aspects: exposure, sensitivity, and AC. Since the exposure and sensitivity are limited by the physical properties of the natural geographic conditions and historic environment, respectively, both attributes are relatively stable and difficult to change based on the protection requirements of the historic environment. However, AC is greatly affected by economics and factors of human capital $[19,47]$ which is relatively simple to optimize. Thus, since it is a critical dimension to reduce the vulnerability under the potential geological hazards risk, this research further focused on the AC when the villages' historic environment bears risks of geological disasters. Its influencing factors and the factors' intensity differences within the region were further analyzed as a basis to offer suitable measures to local conditions.

\subsubsection{Selection of Variables}

This section regards AC as the explained variable. From the three-fold combination of geographical, demographic, and social, this study selected eight factors as explanatory variables to construct a regression model. These included terrain elevation, distance from the township, distance from the highway entrance, population of permanent residents, percentage of the resident population, number of facilities, number of Weibo check-ins, and number of honors. Quantification methods of the data are shown in Table 4.

Table 4. Selection and quantification method of impact factors of AC.

\begin{tabular}{|c|c|c|}
\hline Elements & Indicators & Quantification Methods \\
\hline \multirow{3}{*}{ A Geographical } & A1 Terrain elevation & Use DEM data corresponding to each traditional village's coordinate data. \\
\hline & $\begin{array}{l}\text { A2 Distance from the } \\
\text { township }\end{array}$ & $\begin{array}{l}\text { The coordinate data of township points are sorted out from the POI data } \\
\text { of Lishui, and we use ArcGIS to calculate the straight distance between } \\
\text { the township and the village. }\end{array}$ \\
\hline & $\begin{array}{l}\text { A3 Distance from the } \\
\text { highway entrance }\end{array}$ & $\begin{array}{l}\text { The coordinate data of high-speed toll stations are sorted out from the } \\
\text { POI data of Lishui, and we used ArcGIS to calculate the straight distance } \\
\text { between the high-speed toll station and the village. }\end{array}$ \\
\hline \multirow[b]{2}{*}{ B Demographics } & $\begin{array}{l}\text { B1 Population of } \\
\text { permanent residents }\end{array}$ & $\begin{array}{l}\text { Directly extracted from Chinese traditional village survey registration } \\
\text { form of Lishui. }\end{array}$ \\
\hline & $\begin{array}{l}\text { B2 Percentage of the } \\
\text { resident population }\end{array}$ & $\begin{array}{l}\text { It refers to the ratio of resident population to household registration } \\
\text { population, which could be directly extracted from the Chinese } \\
\text { traditional village survey registration form of Lishui. }\end{array}$ \\
\hline \multirow{3}{*}{ C Social } & C1 Number of facilities & $\begin{array}{l}\text { Using ArcGIS's location selection tool, we selected the POI within } 2 \mathrm{~km} \text { of } \\
\text { each traditional village point, and then spatial summed them to obtain } \\
\text { the number of facilities. }\end{array}$ \\
\hline & $\begin{array}{l}\text { C2 Number of Weibo } \\
\text { check-ins }\end{array}$ & $\begin{array}{l}\text { To a certain extent, this data could represent network attentions and visitor } \\
\text { numbers. Importing Lishui's Weibo check-in data into ArcGIS, we created a } \\
2 \mathrm{~km} \text { buffer based on each traditional village point, and then spatially } \\
\text { summed them to obtain the number of Weibo check-ins of each village. }\end{array}$ \\
\hline & C3 Number of honors & $\begin{array}{l}\text { It refers to the number of honors at or above the provincial or national } \\
\text { level, which could be directly extracted from Chinese traditional village } \\
\text { survey registration form of Lishui. }\end{array}$ \\
\hline
\end{tabular}

\subsubsection{Analysis of Impact Factors}

The eight selected impact factors were considered as independent variables, and the value of AC was considered as the dependent variable and used to build the OLS analysis model. The variance inflation factor (VIF) of each parameter of the model was far lower than 7.5 (Table 5), indicating that the variables were set reasonably and that no multicollinearity problem existed. Moreover, the goodness-of-fit test yielded an $R^{2}$ of 0.34 (Table 5) and the residuals were normally distributed (Figure 6), indicating that there was no heteroscedasticity problem and the model was stable. 
Table 5. Summary of OLS results: model variables and diagnostics.

\begin{tabular}{|c|c|c|c|c|c|c|c|}
\hline Variable & Coefficient & $\begin{array}{l}\text { Standard } \\
\text { Error }\end{array}$ & t_Statistic & Robust_Pr & VIF & \multicolumn{2}{|c|}{ OLS Diagnostics } \\
\hline Intercept & 2.67567 & 0.345 & 7.751 & $0.000000^{* * *}$ & - & $\begin{array}{l}\text { Number of } \\
\text { observations }\end{array}$ & 148 \\
\hline A2 Distance from the township & 0.00007 & 0.000 & 2.727 & $0.007257 * * *$ & 1.115 & $\operatorname{Adj} R^{2}$ & 0.297 \\
\hline A3 Distance from the highway entrance & -0.00002 & 0.000 & -2.558 & $0.017020 * *$ & 1.199 & F-Prob & $0.000 *$ \\
\hline B1 Population of permanent residents & -0.00009 & 0.000 & -0.581 & 0.721 & 2.288 & Wald-Prob & 0.000 * \\
\hline C2 Number of Weibo check-in & -0.00013 & 0.000 & -0.492 & 0.602 & 1.665 & $\mathrm{AICc}$ & 383.520 \\
\hline C3 Number of honors & 0.09538 & 0.037 & 2.589 & 0.057 * & 1.188 & Sigma $^{2}$ & 0.719 \\
\hline
\end{tabular}

${ }^{*}$ Correlation is significant at the 0.1 level; ${ }^{* *}$ correlation is significant at the 0.05 level; ${ }^{* * *}$ correlation is significant at the 0.01 level.

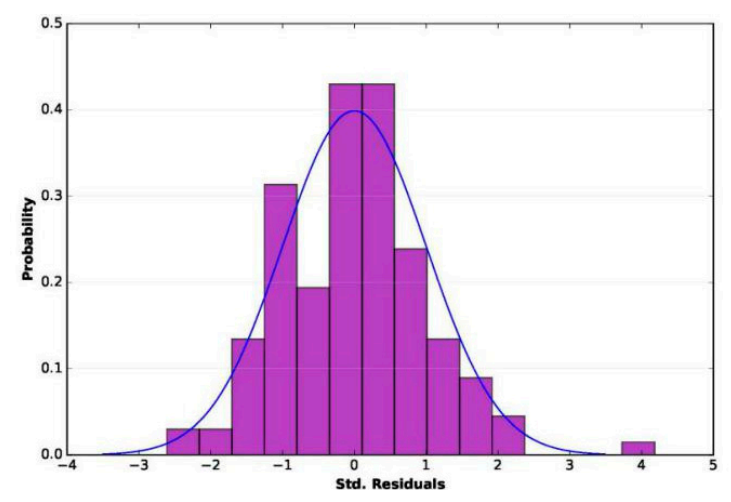

Figure 6. Histogram of standardized residuals.

Both Koenker (BP)-Prob and Wald statistics were significant $(p<0.01$; Table 5). Therefore, the overall model was statistically significant, and the coefficient significance of the variables could be determined according to the value of robust probability (Robust_Pr). The column (Robust_Pr) includes five influencing factors that passed the significance test: distance from the township, distance from the expressway entrance, percentage of the resident population, number of facilities, and number of honors. Among these, the percentage of the resident population and the distance from the township were significantly positively correlated with the AC of affected villages.

\subsubsection{Spatial Variation of the Impact Factor}

Global spatial autocorrelation analysis for AC values showed that Moran's I index was 0.169, and the $p$-value was 0.001 . This shows that the historic environmental risk response capacity in Lishui has a significant spatial clustering effect with a strong positive correlation. Local spatial autocorrelation analysis showed that significant spatial heterogeneity still exists. Therefore, the GWR model was further used to study the spatial differences of the impact factors of $\mathrm{AC}$ which include the five explanatory variables that passed the $10 \%$ significance test in the OLS model.

The results of the GWR showed that the $R^{2}$ was 0.42 , indicating an increase of $24 \%$ compared with OLS. Moreover, as indicated by the spatialization of the regression coefficients of the GWR model (Figure 7a), the range of standardized residual values of the local regression was $(-3.21,4.91)$, $98.6 \%$ of which ranged within $(-2.5,2.5)$. These ranges identified the GWR model as robust and excellent. Moreover, the AICC of the GWR model was 376.22, indicating a decrease of 7.3. According to Fotheringham's evaluation criteria [51], if the AICC value obtained from the GWR model decreased by more than three from that of the OLS, the GWR model is superior. Thus, the GWR model was identified as more accurate. 


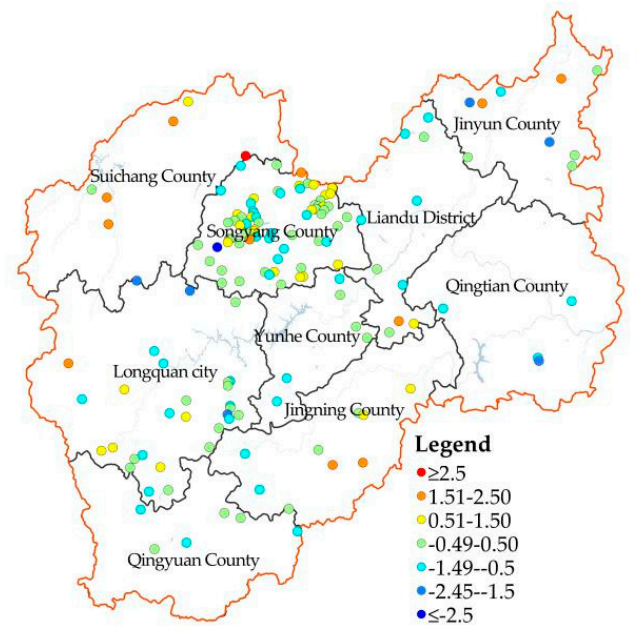

(a)

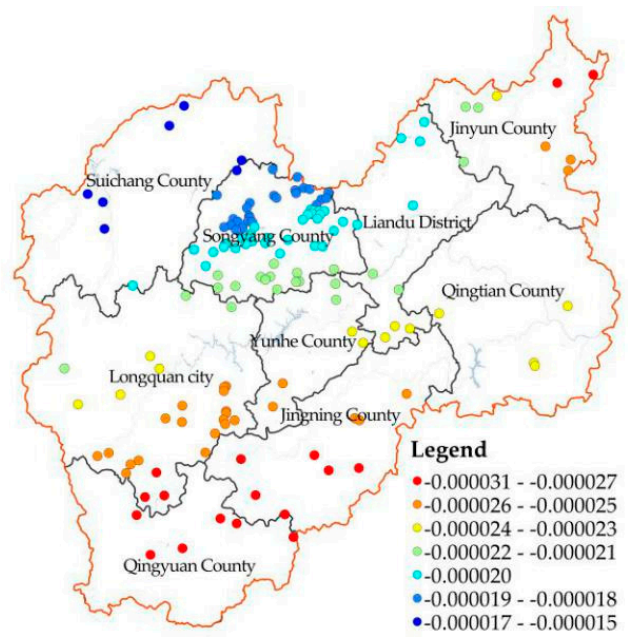

(c)

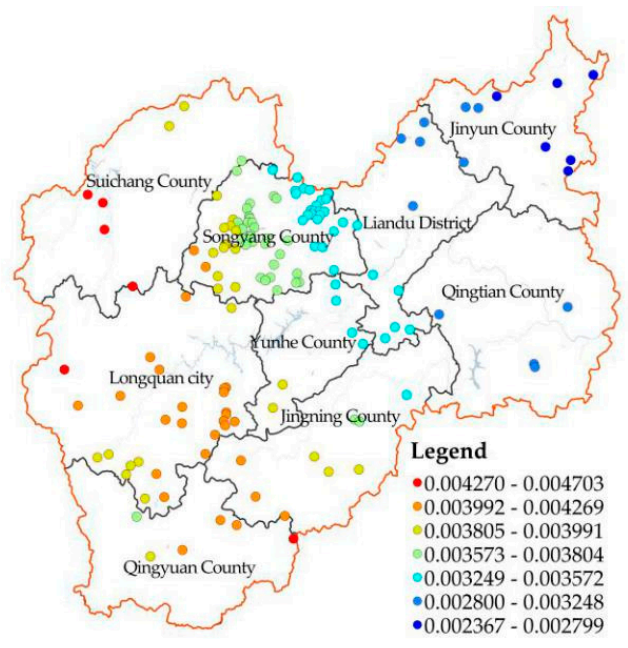

(e)

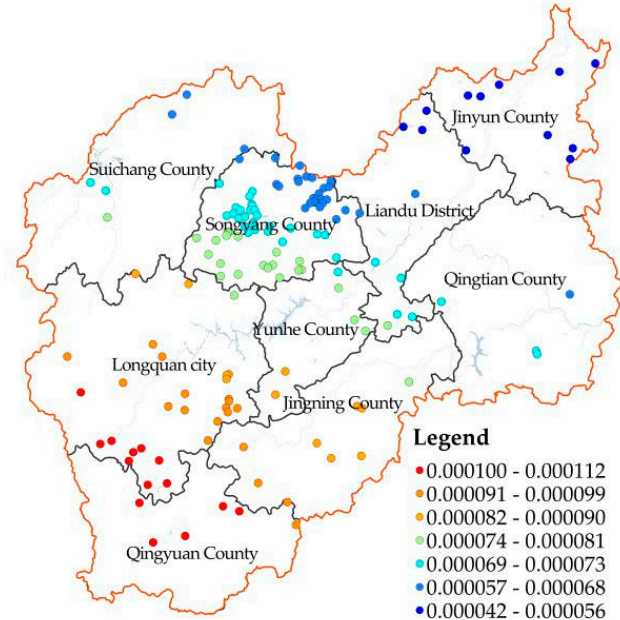

(b)

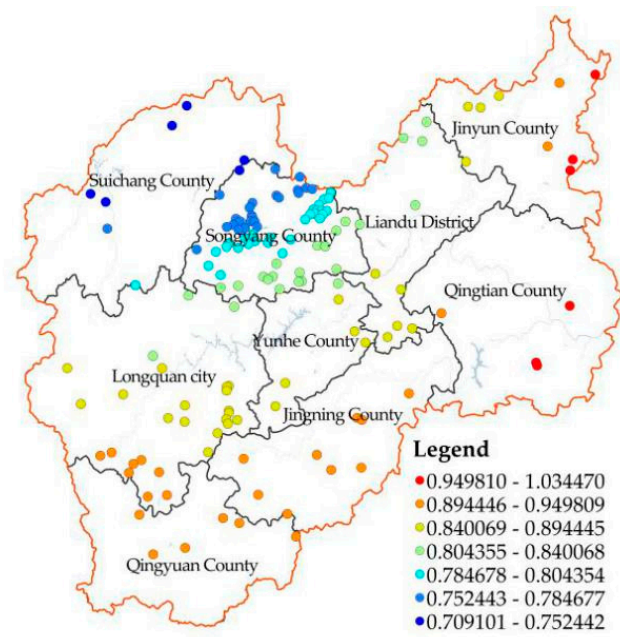

(d)

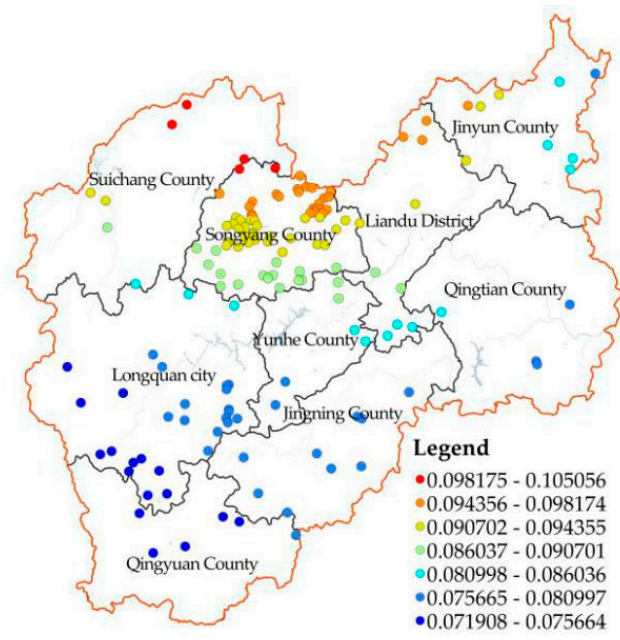

(f)

Figure 7. Spatial distribution of standardized residuals and regression coefficients of the GWR model. (a) Standardized residuals; (b) distance from the township; (c) distance from the highway entrance; (d) percentage of the resident population; (e) number of facilities; (f) number of honors. 
Calculating the GWR model clarified that the difference between the maximum and minimum values of the regression coefficients of each influencing factor was large, indicating a significant spatial difference (Table 6). Furthermore, their median and average values were close to each other in the same directions, illustrating that the influencing properties of each variable were similar for the Lishui area. Moreover, the influence of explanatory variables on the local geographical spaces varied strongly (Figure 7B-F). Among these variables, the distance from the township and the distance from the highway entrance exerted the most notable influences on the south of Lishui, while the percentage of the resident population, the number of facilities, and the number of honors exerted the most considerable influences on the northeast, the middle, and the north of Lishui, respectively.

Table 6. Statistics of regression coefficient of the GWR model.

\begin{tabular}{ccccccc}
\hline Variable & Minimum & $\begin{array}{c}\text { Upper } \\
\text { Quartile }\end{array}$ & Median & $\begin{array}{c}\text { Lower } \\
\text { Quartile }\end{array}$ & Maximum & Mean \\
\hline Distance from the township & $4.2 \mathrm{E}-05$ & $6.7 \mathrm{E}-05$ & $7.2 \mathrm{E}-05$ & $8.8 \mathrm{E}-05$ & $1.1 \mathrm{E}-04$ & $7.6 \mathrm{E}-05$ \\
Distance from the highway entrance & $-3.1 \mathrm{E}-05$ & $-2.5 \mathrm{E}-05$ & $-2.2 \mathrm{E}-05$ & $-2.0 \mathrm{E}-05$ & $-1.5 \mathrm{E}-05$ & $-2.2 \mathrm{E}-05$ \\
Percentage of resident population & $7.1 \mathrm{E}-01$ & $7.9 \mathrm{E}-01$ & $8.2 \mathrm{E}-01$ & $8.8 \mathrm{E}-01$ & $1.0 \mathrm{E}+00$ & $8.4 \mathrm{E}-01$ \\
Number of facilities & $2.4 \mathrm{E}-03$ & $3.5 \mathrm{E}-03$ & $3.7 \mathrm{E}-03$ & $4.0 \mathrm{E}-03$ & $4.7 \mathrm{E}-03$ & $3.7 \mathrm{E}-03$ \\
Number of honors & $7.2 \mathrm{E}-02$ & $7.9 \mathrm{E}-02$ & $9.0 \mathrm{E}-02$ & $9.4 \mathrm{E}-02$ & $1.0 \mathrm{E}-01$ & $8.7 \mathrm{E}-02$ \\
\hline
\end{tabular}

\section{Discussion}

\subsection{Influencing Factors of Adaptive Capacity}

The results of this study showed that the distance from the township and the percentage of the resident population were the two most significant factors related to the AC of a traditional village for historic environmental risk to geological hazards in Lishui. The percentage of the resident population was also identified as a critical influencing factor for the AC of a village [19,24]; however, the distance from the township was a determinant that was not previously identified in the field of historical heritage. This indicates that the reason this previously unidentified factor had a positive correlation with AC was due to the fact of its negative urbanization impact on traditional villages. Many studies have shown that rapid urbanization [7] and convenient transportation [57] will lead to an express outflow of the population from traditional villages. Therefore, it seems that instead of helping the local economy, the greater effect of urbanization and the more convenient transportation resulting from the smaller distance to the township will make indigenous people more inclined to leave the village to work and live in townships. This significantly reduces the occupancy rate of traditional residential buildings thus weakening the AC of historic environmental risks.

More interestingly, this study showed that terrain elevation, an essential negative correlation factor for the transportation risk coping abilities of villages [25], was irrelevant to villages' AC of historic environmental risk. A possible explanation for this might be that the higher the altitude, the less convenient transportation will be. Although a higher altitude limits the economic growth of a village, it also limits the loss of population through inconvenient traffic, thus guaranteeing the occupancy rate of traditional houses. Therefore, its overall impact on AC was not apparent.

\subsection{Suggestions on the Classification Strategies of High Vulnerability Clusters}

The main purpose of this study was to provide a basis for the classification of the fragile historic environment in traditional villages. Prior studies have highlighted the importance of vulnerability-reducing strategies. For instance, based on the evaluation of three villages, Zhou [26] introduced all types of suitable vulnerability enhancements for the landscapes of traditional villages in the aspects of folk culture, tourism development, and local culture inheritance. Furthermore, Jiang et al. [19] established management priorities to improve the local adaptation capabilities to geological disasters through a standard classification of high vulnerability with low adaptation capabilities. However, very few papers have explained how to develop reasonable classification strategies 
by specifying the regional spatial differences of vulnerability. Based on local spatial correlation analysis, this study identified three distinct high-vulnerability clusters in the spatial pattern of HEVTVs for Lishui (Figure 5). Appropriate agglomeration may encourage traditional villages to effectively reduce vulnerabilities and can convince the regional government to invest shared resources into the High-High $(\mathrm{H}-\mathrm{H})$ clusters, thus maximizing economic benefits and generate a virtuous cycle. Therefore, this study developed corresponding strategies for each zone by overlaying the spatial intensity variation of the influencing factors of $\mathrm{AC}$, distinguishing the determinants, proposing relevant resource sharing, and effectively upgrading the AC of cluster villages. The specific zoning strategies are as follows:

For traditional villages in the first $\mathrm{H}-\mathrm{H}$ cluster zone, honors should be declared and their popularity as a whole should be promoted. This high-vulnerability group of villages is located in the middle of Songyang, with medium to high values of vulnerability, exposure, and sensitivity, and a low AC value. The results of this study indicate the distance from townships and the percentage of the resident population as key influencing factors of AC. Both factors have a relatively low degree of influence in this region, while the number of honors has the most significant impact (Figure $7 \mathrm{~b}, \mathrm{~d}, \mathrm{f}$ ). Further data review and field visits showed that traditional villages in this zone are close to the highway entrance, and offer convenient transportation. Also, the main source of village collective income has shifted from traditional agriculture and forestry to tourism. Therefore, the more high-level honors traditional villages receive, the higher the village's popularity and the more significantly tourism economy and human capital will be promoted. Thus, this suggests the development of honor declaration, the promotion of popularity for this group of traditional villages, and the promotion of the economy and human capital within tourism development, to strengthen the historic environmental risk response capabilities of villages.

For the traditional villages in the second $\mathrm{H}-\mathrm{H}$ cluster, shared facilities should be constructed. This high-vulnerability group of villages is located in the southwest of Songyang with medium to high values of vulnerability and exposure, low sensitivity, and extremely low to medium values of AC. Combining the spatial difference analysis of the impact factors of AC showed that in this area, the impact of the number of facilities was significant (Figure 7e). Through data review and field visits, it was established that villages here are located on administrative borders with a relatively closed mountain society and low economic prospects. Moreover, in recent years, because of a lack of essential living facilities, a trend of permanent population reduction affects this area. Therefore, shared public facilities should be increased, thus bringing livable infrastructure for the inhabitants, and slowing down the loss of villagers. This will ensure the human capital basis for the improvement of their historic environmental risk-response capabilities.

For the traditional villages in the third $\mathrm{H}-\mathrm{H}$ cluster, a sharing of traffic should be set-up in connection with the highway entrance. This group of villages is located at the junction of Longquan and Qingyuan, with high exposure and sensitivity. The AC value is much lower than that of the former two groups, which results in an overall very high vulnerability. According to the statistical data, the villages are far away from the highway entrance, and thus suffer from low economic prospects and severe population loss because of the close distance from townships. Moreover, based on the spatial intensity variation of the influencing factors of $A C$, both the distance from the township and the distance from the highway entrance exert a very high impact on this area (Figure $7 \mathrm{~b}, \mathrm{c}$ ). It is not possible to change the distance between villages and towns; therefore, decision-makers should focus on strengthening shared transportation connections of traditional villages and highway entrances, and on introducing tourists after increasing accessibility. This will lead to an economic improvement for villages, thus effectively improving their coping capacity.

\subsection{Contributions and Implications}

This study focused on the issue that the historic environment in traditional villages, generally with an underdeveloped economy and mountainous terrains, is prone to fall into the double dilemma of high exposure and low AC. The contributions and implications of this study are as follows: first, 
this study evaluated vulnerability to geological disasters for the hazard-affected bodies of the villages' historic environments. A scope expansion of the specific vulnerability assessment index system was provided, which might help to improve the theoretical method for the protection and inheritance of the historic environment. Second, compared with previous studies that only considered "exposure-internal vulnerability" [26], "exposure-risk awareness" [30], and "sensitivity-adaptive capacity" [37], this study started from the coupled human-environment system, concentrating not only on the historic environment itself but also on AC to address the risk. Its comprehensive assessment system with the three dimensions of "exposure, sensitivity, and AC", may be of practical significance for their protection, inheritance, activation, and sustainable development. Third, the scientific measurement of 148 traditional villages in Lishui offers empirical evidence on a large scale but small-unit evaluation of HEVTVs. This accurate classification of HEVTV, at a district level, offers a frame of reference for many other regions that face similar problems. Fourth, the results of the spatial variation of HEVTVs and the influencing factors of AC may form the basis for regional emergency management strategies and may also be useful for other traditional village gathering areas with hidden geological hazards.

\subsection{Limitations and Suggestions for Future Work}

Several questions remain unanswered at present. First, although this study considered human resources and the economic level from the perspective of villagers, neither psychological nor behavioral factors were addressed. Examples thereof are the degree of attention of the local government, the villagers' risk awareness, and their response willingness. Further studies should consider these variables. Secondly, the reasons for various influences of explanatory variables on the local geographical spaces should be further explored, to provide an in-depth scientific analysis and prediction for emergency management in accordance with local conditions.

\section{Conclusions}

While a rich literature has focused on the fragility of whole villages, the vulnerability of the historic environment of villages remains largely uninvestigated. To bridge this gap, this study provided a new conceptual framework and a practical district-level measurement tool for the historic environmental vulnerability of traditional villages.

The historic environmental vulnerability was defined under geological hazards. It was assumed that the historic environment (including traditional buildings and historic landscape elements) is susceptible to damage or negative effects because of the threefold combination of environmental exposure, the lack of anti-disturbance capabilities, and the shortness of risk-coping abilities. Based on this assumption, a quantitative evaluation system was constructed with three criteria: exposure, sensitivity, and AC. These were followed by six primary factors and 13 indexes. Taking Lishui City as the case study area, the degree, the spatial distribution, and their agglomeration characteristics of the HEVTVs were explored. Furthermore, the influencing factors of ACs and the spatial variation of their intensity were identified thus providing an important basis for vulnerability classifications and reductions from a district level. The main conclusions are as follows:

(1) The historic environment of traditional villages in Lishui is vulnerable to geological hazards and the large majority of villages have moderate or above levels of vulnerability. The differences in their HEVTV grades and distributions are distinct, showing a spatial pattern of high in the middle and low in the east and west. Moreover, their vulnerabilities are notably related to the elevation of the terrain so that the vertical differences in the HEVTV values are significant. Villages in Lishui with very high vulnerability are distributed on mid-elevation mountains, which suffer from steep slopes, while low-vulnerability villages are generally on plains at low altitudes;

(2) Spatial autocorrelation identified three remarkable high-high vulnerability cluster groups: in the middle of Songyang, at the junction of Songyang and Longquan, and at the border of Longquan and Qingyuan. Because of the differences in their vulnerability criteria values, targeted zoning strategies should be proposed; 
(3) Five influencing factors were found to be strongly related to the AC of traditional villages, among which the distance from the township and the percentage of the resident population are the two most significant variables. Moreover, these five influencing factors indicated a spatial variation of the impact intensity which could be applied to streamline vulnerability optimization strategies according to local conditions.

Author Contributions: Conceptualization and writing: S.L.; review and editing: J.G.; methodology: W.L.; data curation and visualization: M.B. All authors have read and agreed to the published version of the manuscript.

Funding: This research was funded by the National Natual Science Foundation of China (grant number 51908495).

Conflicts of Interest: The authors declare no conflict of interest.

\section{References}

1. Li, B.; Luo, Q.; Liu, P.; Zhang, J.Q. Knowledge Maps Analysis of Traditional Villages Research in China Based on the Citespace Method. Econ. Geogr. 2017, 37, 207-214.

2. Dewi, L.K.Y. Modeling the Relationships between Tourism Sustainable Factor in the Traditional Village of Pancasari. Procedia Soc. Behav. Sci. 2014, 135, 57-63. [CrossRef]

3. Sesotyaningtyas, M.; Manaf, A. Analysis of Sustainable Tourism Village Development at Kutoharjo Village, Kendal Regency of Central Java. Procedia Soc. Behav. Sci. 2015, 184, 273-280. [CrossRef]

4. Debnath, R.; Bardhan, R. Resource Symbiosis Model through bricolage: A livelihood generation assessment of an Indian village. J. Rural Stud. 2018, 60, 105-121. [CrossRef]

5. Akinciturk, N.; Kilic, M. A study on the fire protection of historic Cumalıkızık village. Int. J. Sustain. High. Educ. 2004, 5, 213-219. [CrossRef]

6. González-Arqueros, M.L.; Mendoza, M.E.; Bocco, G.; Castillo, B.S. Flood susceptibility in rural settlements in remote zones: The case of a mountainous basin in the Sierra-Costa region of Michoacán, Mexico. J. Environ. Manag. 2018, 223, 685-693. [CrossRef]

7. Yingchun, C.; Yukun, Z. Appraisal and Selection of "Chinese Traditional Village" and Study on the Village Distribution. Archit. J. 2013, 12, 44-49.

8. Pan, A. Study on mobility-disadvantage group'risk perception and coping behaviors of abrupt geological hazards in coastal rural area of China. Environ. Res. 2016, 148, 574-581. [CrossRef]

9. Jiang, X. 130 hours do not give up hope-Zhejiang Lishui Lidong village landslide disaster rescue record. China Fire 2015, 22, 22-26.

10. Schneiderbauer, S.; Ehrlich, D. Risk, Hazard and People's Vulnerability to Natural Hazards: A Review of Definitions, Concept and Data; European Commission-Joint Research Centre (EC-JRE): Brussels, Belgium, 2004.

11. Houghton, J.; Meira Filho, L.; Callander, B.; Harris, N.; Kattenberg, A.; Maskell, K. IPCC Climate Change. The IPCC Second Assessment Report; Cambridge University Press: New York, NY, USA, 1996.

12. McCarthy, J.J.; Canziani, O.F.; Leary, N.A.; Dokken, D.J.; White, K.S. (Eds.) Climate Change 2001: Impacts, Adaptation and Vulnerability; Cambridge University Press: Cambridge, UK, 2001.

13. Eakin, H.; Luers, A.L. Assessing the vulnerability of social-environmental systems. Soc. Sci. Electron. Publ. 2006, 5, 365-394. [CrossRef]

14. Handayani, W.; Rudiarto, I.; Setyono, J.S.; Chigbu, U.E.; Sukmawati, A.M.A. Vulnerability assessment: A comparison of three different city sizes in the coastal area of Central Java, Indonesia. Adv. Clim. Change Res. 2017, 8, 286-296. [CrossRef]

15. Jha, R.K.; Gundimeda, H. An integrated assessment of vulnerability to floods using composite index-A district level analysis for Bihar, India. Int. J. Disaster Risk Reduct. 2019, 35, 101074. [CrossRef]

16. Chen, S.; Zha, X.; Bai, Y.; Wang, L. Evaluation of soil erosion vulnerability on the basis of exposure, sensitivity, and adaptive capacity: A case study in the Zhuxi watershed, Changting, Fujian Province, Southern China. Catena 2019, 177, 57-69. [CrossRef]

17. Mejía-Navarro, M.; Wohl, E.E.; Oaks, S.D. Geological hazards, vulnerability, and risk assessment using GIS: Model for Glenwood Springs, Colorado. Geomorphology 1994, 10, 331-354. [CrossRef]

18. Fedeski, M.; Gwilliam, J. Urban sustainability in the presence of flood and geological hazards: The development of a GIS-based vulnerability and risk assessment methodology. Landsc. Urban Plan. 2007, 83, 50-61. [CrossRef] 
19. Jiang, W.; Deng, Y.; Tang, Z.; Cao, R.; Chen, Z.; Jia, K. Adaptive capacity of mountainous rural communities under restructuring to geological disasters: The case of Yunnan Province. J. Rural Stud. 2016, 47, 622-629. [CrossRef]

20. Kaynia, A.M.; Papathoma-Köhle, M.; Neuhäuser, B.; Ratzinger, K.; Wenzel, H.; Medina-Cetina, Z. Probabilistic assessment of vulnerability to landslide: Application to the village of Lichtenstein, Baden-Württemberg, Germany. Eng. Geol. 2008, 101, 33-48. [CrossRef]

21. Valensise, G.; Tarabusi, G.; Guidoboni, E.; Ferrari, G. The forgotten vulnerability: A geology-and history-based approach for ranking the seismic risk of earthquake-prone communities of the Italian Apennines. Int. J. Disaster Risk Reduct. 2017, 25, 289-300. [CrossRef]

22. Ambrosi, C.; Strozzi, T.; Scapozza, C.; Wegmüller, U. Landslide hazard assessment in the Himalayas (Nepal and Bhutan) based on Earth-Observation data. Eng. Geol. 2018, 237, 217-228. [CrossRef]

23. Infante, D.; Confuorto, P.; Di Martire, D.; Ramondini, M.; Calcaterra, D. Use of DInSAR Data for Multi-level Vulnerability Assessment of Urban Settings Affected by Slow-moving and Intermittent Landslides. Procedia Eng. 2016, 158, 470-475. [CrossRef]

24. Zou, J.; Zhu, Q.; Liu, P. The Vulnerability Factors of Tourism Traditional Villages Based on the Interpretation Structural Model. Econ. Geogr. 2018, 38, 219-225.

25. Yang, Q.; Liu, Q.; Yin, S.; Zhang, J.; Yang, X.; Gao, Y. Vulnerability and influencing factors of rural transportation environment in Qinling-Daba mountainous areas: A case study of Luonan county in Shaanxi province. Acta Geogr. Sin. 2019, 74, 1236-1251.

26. Zou, J.; Liu, Y.; Tan, F.; Liu, P. Landscape Vulnerability and Quantitative Evaluation of Traditional Villages: A Case Study of Xintian County, Hunan Province. Sci. Geogr. Sin. 2018, 38, 1292-1300.

27. Zhang, S. Theory and practice of historic environment preservation in Japan. J. Tsinghua Univ. Sci. Technol. 2000, 1, 44-48.

28. Fatiguso, F.; De Fino, M.; Cantatore, E.; Caponio, V. Resilience of historic built environments: Inherent qualities and potential strategies. Procedia Eng. 2017, 180, 1024-1033. [CrossRef]

29. Sesana, E.; Gagnon, A.S.; Bonazza, A.; Hughes, J.J. An integrated approach for assessing the vulnerability of World Heritage Sites to climate change impacts. J. Cult. Herit. 2020, 41, 211-224. [CrossRef]

30. Pavlova, I.; Makarigakis, A.; Depret, T.; Jomelli, V. Global overview of the geological hazard exposure and disaster risk awareness at world heritage sites. J. Cult. Herit. 2017, 28, 151-157. [CrossRef]

31. Yuan, C.; He, Y.; Feng, Y.; Wang, P. Fire hazards in heritage villages: A case study on Dangjia Village in China. Int. J. Disaster Risk Reduct. 2018, 28, 748-757. [CrossRef]

32. Ortega, J.; Vasconcelos, G.; Rodrigues, H.; Correia, M.; Ferreira, T.M.; Vicente, R. Use of post-earthquake damage data to calibrate, validate and compare two seismic vulnerability assessment methods for vernacular architecture. Int. J. Disaster Risk Reduct. 2019, 39, 101242. [CrossRef]

33. Mosoarca, M.; Onescu, I.; Onescu, E.; Azap, B.; Chieffo, N.; Szitar-Sirbu, M. Seismic vulnerability assessment for the historical areas of the Timisoara city, Romania. Eng. Fail. Anal. 2019, 101, 86-112. [CrossRef]

34. Pataki, B.; Zsuffa, I.; Hunyady, A. Vulnerability assessment for supporting the revitalisation of river floodplains. Environ. Sci. Policy 2013, 34, 69-78. [CrossRef]

35. Mattei, G.; Rizzo, A.; Anfuso, G.; Aucelli, P.P.C.; Gracia, F.J. A tool for evaluating the archaeological heritage vulnerability to coastal processes: The case study of Naples Gulf (southern Italy). Ocean Coast. Manag. 2019, 179, 104876. [CrossRef]

36. Du, F.; Okazaki, K. Building improvement responses to multi-hazard risk in the historic Dali Dong Village, Guizhou, China. Int. J. Disaster Risk Reduct. 2016, 19, 64-74. [CrossRef]

37. Shukla, R.; Sachdeva, K.; Joshi, P.K. Inherent vulnerability of agricultural communities in Himalaya: A village-level hotspot analysis in the Uttarakhand state of India. Appl. Geogr. 2016, 74, 182-198. [CrossRef]

38. Lishui Municipal Statistics Bureau. Lishui Statistical Yearbook; China Statistics Press: Beijing, China, 2018.

39. Xu, H.; Zhu, Y.; Zhou, H. On the practice and thinking of the comprehensive treatment of geological disasters in Lishui City, Lishui City's “Life Project" of geological disaster prevention and control with "big move and quick treatment". Zhejiang Land Resour. 2018, 12, 20-23.

40. Gaode Open Platform. Available online: http://lbs.amap.com/ (accessed on 2 January 2020).

41. Geographical Information Monitoring Cloud Platform. Available online: www.dsac.cn (accessed on 2 January 2020). 
42. Resource and Enviroment Data Cloud Platform. Available online: http://www.resdc.cn (accessed on 2 January 2020).

43. Hu, Y.; Chen, S.; Cao, W.; CAO, C. The Concept and Cultural Connotation of Traditional Villages. Urban Dev. Stud. 2014, 1, 10-13.

44. Ministry of Housing and Urban-rural Development of the People's Republic of China. Available online: http://www.mohurd.gov.cn/wjfb/201404/t20140429_217798.html (accessed on 2 January 2020).

45. Liu, L.; Yin, K.L. Analysis of rainfall infiltration mechanism of rainstorm landslide. Rock Soil Mech. Wuhan 2008, 29, 1061.

46. Jinliang, H.; Shuren, W.; Huabin, W. Preliminary study on geological hazard chains. Earth Sci. Front. 2007, 14, 11-20.

47. Peng, L.; Xu, D.; Wang, X. Vulnerability of rural household livelihood to climate variability and adaptive strategies in landslide-threatened western mountainous regions of the Three Gorges Reservoir Area, China. Clim. Dev. 2019, 11, 469-484. [CrossRef]

48. Jurjonas, M.; Seekamp, E. Rural coastal community resilience: Assessing a framework in eastern North Carolina. Ocean Coast. Manag. 2018, 162, 137-150. [CrossRef]

49. Adger, W.N. Vulnerability. Glob. Environ. Chang. 2006, 16, 268-281. [CrossRef]

50. Anselin, L.; Kelejian, H.H. Testing for spatial error autocorrelation in the presence of endogenous regressors. Int. Reg. Sci. Rev. 1997, 20, 153-182. [CrossRef]

51. Anselin, L. The local indicators of spatial association: LISA. Geogr. Anal. 1995, 27, 93-115. [CrossRef]

52. Kenney, J.F.; Keeping, E.S. Linear Regression and Correlation. In Mathematics of Statistics, 3rd ed.; Van Nostrand: Princeton, NJ, USA, 1962; pp. 252-285.

53. Demek, J. Manual of Detailed Geomorphological Mapping; Cambridge University Press: London, UK, 1972; p. 344 .

54. Brunsdon, C.; Fotheringham, S.; Charlton, M. Geographically weighted regression- modelling spatial nonstationarity. J. R. Stat. Soc. 1998, 47, 431-443. [CrossRef]

55. Jenks, G.F. The Data Model Concept in Statistical Mapping. In International Yearbook of Cartography; Frenzel, K., Ed.; George Philip \& Son: London, UK, 1967; Volume 7, pp. 186-190.

56. Cheng, W.; Zhou, C.; Chai, H.; Zhao, S.; Liu, H.; Zhou, Z. Research and compilation of the Geomorphologic Atlas of the People's Republic of China (1:1,000,000). J. Geogr. Sci. 2011, 21, 89-100. [CrossRef]

57. Kang, J.Y.; Zhang, J.H.; Hu, H.; Zhou, J.; Xiong, J. Analysis on the spatial distribution characteristics of Chinese traditional villages. Prog. Geogr. 2016, 35, 839-850. 